\title{
REGRESAR POR EL CAMINO VIEJO. RETORNADAS Y RECONSTRUCCIÓN DE LA VIDA EN Los Montes de María
}

\section{Going Back Down the Old Road. Returning and Reconstruction of LifE IN MONTES DE MARÍA}

\author{
María Angélica Garzón-Martínez* \\ DOI: http://dx.doi.org/10.29043/liminar.v19il.789
}

\begin{abstract}
Resumen: En el artículo se controvierte la mirada hegemónica de los estudios de retorno de población que lee a las mujeres como simples "seguidoras" en el proceso, y no como parte activa de este. A partir del posicionamiento feminista, se analizan prácticas de cuidado y reconstrucción de mujeres retornadas en la región de Montes de María, Colombia. Mediante un acercamiento testimonial, se exploran iniciativas organizativas, liderazgos y emergencias de conciencia política. Se concluye que las agencias de mujeres retornadas son fundamentales para consolidar apuestas por permanecer desde una vida digna, resignificar historias de violencia asociadas a la violencia del conflicto armado y reconstruir en medio de este.
\end{abstract}

Palabras clave: migración de retorno, restablecimiento, organización de mujeres, trabajo comunitario, liderazgo político, feminismo, movimientos feministas.

Abstract: The article disputes the hegemonic view of returned-population studies that see women as simple "followers" in the return process and not as an active part therein. From a feminist perspective, the author analyzes practices involving caring and rebuilding by the women who have returned to the Montes de María region in Colombia. Through a testimonial approach, the author explores organizational initiatives, leadership, and emerging political awareness. The article's principal conclusion is that the agencies serving returned women are essential to consolidate their commitment to remain by maintaining a dignified life, resignify the histories of violence associated with the brutal armed conflict, and rebuild in the midst of such conflict.

Keywords: return migration, resettlement, women's associations, community work, political leadership, feminism, feminist movements.

\footnotetext{
* María Angélica Garzón Martínez. Doctora en Ciencias Humanas y Sociales por la Universidad Nacional de Colombia. Investigadora del Grupo Interdisciplinario de Investigaciones Arqueológicas e Históricas, Colombia, y docente de la Universidad Pedagógica y Tecnológica de Colombia (UPTC). Temas de especialización: reconstrucción de memorias, migraciones de retorno y conflictos sociales. Correo electrónico: maria.garzon03@uptc.edu.co. ORCID: https:/orcid. org/0000-0003-1753-1476
}

Enviado a dictamen: 13 de abril de 2020. Aprobación: 25 de agosto de 2020. 


\section{Introducción: un pueblo desolado}

Regresar a mi pueblo/ Por el camino viejo

Y recoger mis pasos/Y empezar de nuevo

Andrés Castro y Carlos Vives, "La foto de los dos",

2013

Yo tengo un sueño y es volver a la tierra, a donde tengo mi casa, organizar a las mujeres... Mujer retornada, 1997.

$\mathrm{U}$ n pueblo desolado en medio de un paisaje fantasmal, casas destruidas por el abandono, "enmontadas" por la maleza, caminos de tierra que cuentan historias de huida y retorno; brisas que bajan desde la montaña y que juegan con las ramas de las ceibas, aquellos árboles que, imponentes, se mantienen de pie pese a todo. Hay tensión en el aire, tal vez miedo y expectativa. Soy testiga de un evento arriesgado, peligroso en tanto que no existen condiciones $y$, sin embargo, tan importante en la tarea histórica de seguir luchando por una vida digna en el propio territorio. Funcionarios de organismos gubernamentales acompañan la caravana para garantizar algo de "seguridad" a esta; también se hacen presentes organismos internacionales como la Cruz Roja, por lo que pueda suceder. El sol empieza a aparecer iluminando los cuerpos de las caminantes que, con motetes en mano, ${ }^{1}$ se acercan cada vez más a su destino. Son un grupo de mujeres que retornan al lugar de donde fueron desplazadas por la violencia del conflicto armado, a pesar del riesgo de semejante empresa. Ellas se hacen presentes, le dicen a la muerte: "iCarajo, respeta!", ${ }^{2}$ y con sus pasos resignifican las "rutas del horror", ese camino viejo, en "rutas de vida" (Centro de Memoria Histórica, s/f).

La región de Montes de María, ubicada en el caribe colombiano entre los departamentos de Sucre y Bolívar, ${ }^{3}$ es un territorio campesino que ha sufrido de manera tenaz los mecanismos y efectos de la violencia del conflicto armado en el país al ser una geografía en disputa por diferentes grupos armados — guerrillas, paramilitares y ejército nacional - gracias a su ubicación estratégica y su riqueza en términos de agricultura, recursos natu- rales y variedad de fauna. Poblada históricamente por pueblos indígenas, afrodescendientes y campesinos, la historia de Los Montes de María ha estado cruzada por los intereses de poderes que buscan expropiar el territorio, entre los que se cuentan el régimen de terratenientes, las grandes empresas agroindustriales y ganaderas, el narcotráfico y los paramilitares (PNUD Colombia, 2010), y las resistencias y proyectos de transformación de sus habitantes. Dichos poderes y sus dinámicas operan a través del desplazamiento forzado de la población, el cual se intensificó durante las últimas décadas del siglo XX, para hacer de Los Montes de María uno de los territorios con mayor expulsión de población del país (Garzón, 2019).

Asimismo, Los Montes de María son el escenario de múltiples procesos de retorno, los cuales vienen dándose de manera casi paralela al desplazamiento forzado, en circunstancias adversas por la falta de garantías y, muchas veces, por el nulo apoyo estatal. En Colombia puede hablarse de retornos individuales, masivos, con la finalidad de permanecer, para cerciorarse del estado de cultivos; retornos de corto plazo, de largo plazo; retornos que a veces cuentan con apoyo institucional, retornos que no son registrados por el radar estatal; retornos que vuelven a sufrir del desplazamiento forzado, etcétera. Pese a su complejidad, es posible afirmar que la mayoría de los retornos de población en el país se hacen por iniciativa de las personas desplazadas, quienes optan por regresar ante el cansancio de las exigencias de la vida en la ciudad, la posibilidad de salvaguardar patrimonios que aún conservan en el lugar de expulsión y una oferta institucional que se presenta en términos de "reparación” y "restitución de tierras" (Garzón, 2019).

Ante unas condiciones materiales, económicas y políticas que poco favorecen la consolidación de retornos en el país, es esencial la indagación sobre el retorno y las dinámicas con las que se desarrollan estos procesos, las apuestas que se movilizan a partir de ellos y las formas mediante las cuales se gestionan la serie de luchas que propone regresar a territorios donde el conflicto armado y sus causas no terminan de resolverse. Sin embargo, la mayoría de la investigación social y humanística (a propósito), desarrollada en 
los últimos diez años en Colombia, tipifica el retorno como una apuesta masculina en la que los hombres son protagonistas, pues sus liderazgos e intereses marcan las bitácoras del retorno, el diseño de sus estrategias $y$, al final, todo el andamiaje que se requiere para retornar. ${ }^{4}$ Como siempre, desde la visión androcéntrica hegemónica en la producción de conocimiento, el rol de las mujeres en los procesos de retorno se invisibiliza o a lo sumo se asocia a los trabajos de cuidado que, no obstante, son fundamentales para la reproducción de la vida (Federici, 2010).

Por ello, desde un posicionamiento feminista, en este artículo deseo dar cuenta del papel de las mujeres en los proyectos de retorno en la región - retornos imaginados, retornos concluidos-, centrándome en los procesos de resignificación de la existencia dados desde prácticas concretas enraizadas en la cultura y la vida cotidiana, que se proyectan a la vida comunal y al tejido social, siendo ellos un ejercicio de agencia y transformación que da cuenta de apuestas vitales que son feministas aunque no lleven ese nombre, porque tampoco es necesario. Con tal fin, se retoma un acercamiento testimonial pensando el testimonio como experiencia narrada (Bach, 2010), construido a través de dos vías: una es la etnográfica, que se deriva del trabajo de campo realizado para mi tesis doctoral en la región entre los años 2016 y 2017, y otra la vía documental, en la cual retomo testimonios de fuentes secundarias con el ánimo de consolidar la narrativa aquí presentada. Dicha narrativa apuesta a tejer diversas voces de mujeres organizadas que, como afirman las tejedoras de Mampujan (Bolívar, Colombia), se han llenado de sueños y de imágenes de un viejo mundo y de un nuevo mundo que está en construcción.

Con fines expositivos, el artículo se divide en cuatro apartados. En el primero, "Por el camino viejo", se contextualiza el problema del desplazamiento forzado de población en la región de Montes de María, se establece una breve cronología del conflicto armado en este territorio, son ubicadas las condiciones para el retorno, y se introduce la discusión sobre la mirada que desde los estudios de movilidad han realizado respecto al papel de las mujeres en procesos de este tipo.
En el segundo apartado, "Recoger mis pasos", analizo, desde la experiencia de las mujeres tejedoras de Mampujan, las prácticas desplegadas por estas mujeres para reconstruirse y reconstruir no como víctimas de la violencia, sino como agentes de cambio en un retorno imaginado desde la remembranza del pasado. En "Empezar de nuevo", el tercer apartado, expongo los retos vitales, colectivos y organizativos que el retorno propone a las mujeres desde la cotidianidad, y cómo desde allí ellas construyen conciencia política, liderazgo y apuestas por permanecer. En el último apartado, "Regresar a casa", sintetizo y recojjo las reflexiones propuestas en este artículo.

\section{Por el camino viejo}

El desplazamiento forzado es una estrategia militar, económica, política y de control para expropiar a las poblaciones rurales, en especial, de sus tierras, pertenencias, animales, cultivos, referentes sociales y culturales y lazos de solidaridad, con la finalidad de crear, mantener, fortalecer o disputar estructuras orientadas al control territorial y poblacional (Pécaut, 2002). En el caso de Los Montes de María, los desplazamientos forzados pueden rastrearse de forma importante a partir de la década de los años ochenta del siglo XX, cuando en la región se intensificó la lucha territorial entre diferentes guerrillas -Fuerzas Armadas Revolucionarias de Colombia (FARC), Ejército Revolucionario del Pueblo (ERP) y Ejército de Liberación Nacional (ELN) - y una década después cuando arribaron grupos paramilitares - Autodefensas Campesinas de Córdoba y Uraba (ACCU) - , en alianza con el narcotráfico, algunos grandes terratenientes y la clase política corrupta.

Una vez que el cuadro se complejiza, los desplazamientos forzados están a la orden del día:

A partir de 1996 la violencia se incremento vertiginosamente en la región. Las masacres, los asesinatos selectivos, los homicidios indiscriminados, el desplazamiento forzado y las amenazas llenaron de terror los campos y poblados de Los Montes de María. Entre 1997 y 2003, los paramilitares de la región des- 
plazaron a unas 100.000 personas y mataron al menos 115 en masacres como las de Las Palmas, Bajo Grande, La Sierrita, El Salado, Mampuján, El Chengue y Macayepo, según información de organizaciones defensoras de los derechos humanos (PNUD Colombia, 2010:19).

Para la década de los años noventa del siglo XX, las autodefensas inician su proyecto de toma del territorio colombiano a "sangre y fuego". Los Montes de María no resultan exentos de dicho proyecto; por el contrario, se convierten en uno de los motines más preciados. Unas veces actuando solos, otras en estrech a complicidad con la fuerza pública, los grupos paramilitares despliegan su furia en esta región cometiendo todo tipo de violaciones a los derechos humanos e infracciones al derecho internacional humanitario. Pero ello no lo hacen sin enfrentar fuertes oposiciones, pues Los Montes de María también se han caracterizado por las múltiples luchas de sus habitantes por acceder al recurso de la tierra, por movimientos sociales populares, grupos religiosos, étnicos, estudiantes, sindicalistas y organizaciones de mujeres que han resistido, negociado, dialogado en pro de edificar una paz duradera o, por lo menos, la humanización del conflicto (Garzón, 2019).

A esto se suma, durante el gobierno del presidente Álvaro Uribe Vélez (2002-2008), una serie de acciones estatales dirigidas a la pacificación de los territorios, la superación del conflicto armado y la necesidad de reparar a las víctimas de dicho conflicto; específicamente, políticas de retorno que pretenden favorecer el regreso de las poblaciones expulsadas por la violencia a sus territorios (Caicedo et al., 2006). Para el caso del presente artículo, el retorno es definido como la lucha que adelantan poblaciones víctimas del desplazamiento forzado en torno a la defensa de la tierra, el territorio y la vida, con el fin de permanecer. Retornar a un contexto en el que las condiciones que propiciaron el desplazamiento forzado se encuentran vigentes significa una lucha no solo por volver, también por re-hacer la vida en el amplio espectro de lo que ello supone, además de quedarse a defender reivindicaciones de la tradición política latinoamericana campesina, indígena y afro en torno al hecho de que "la tierra es de quien la trabaja", y propiciar lecturas territoriales a propósito de la cultura y la vida rural (Garzón, 2019).

Por ello, contrario a lo que suele postularse en los estudios de movilidad (Blitz, 1999; Coutin, 2016; Pettersson, 2000), el retorno no es solo un trayecto de regreso; es un proceso complejo, tanto en términos de lo que significa volver a un lugar marcado por la violencia del conflicto armado y el abandono del tiempo transcurrido durante el desplazamiento forzado, como por las condiciones políticas, económicas, sociales y subjetivas en las que se desarrolla y la necesidad de re-tejer el tejido social como estrategia principal de sobrevivencia y permanencia. Para esto, el retorno exige por los menos dos niveles de organización social: por un lado, la organización social construida de manera formal a través de organizaciones no gubernamentales, por ejemplo, gracias a las cuales se visibilizan los retornos, se pide ayuda estatal, inciden en política pública, gestionan solicitudes de diversos recursos y exigen derechos; por otro lado, la organización solidaria dada en lo cotidiano, responsable, entre otras tareas, de adecuar las condiciones físicas de los lugares a los que se retorna, proveer de alimentos y agua, el cuidado de infantes y adultos mayores, hacer rondas de seguridad, reiniciar el trabajo agrícola, en suma, el trabajo de reproducción de la vida que garantiza la permanencia en el territorio.

Como salta a la vista, en esta segunda forma de organización social las mujeres cumplen una misión importante, ya que sobre ellas recae ese trabajo de reproducción de la vida. En este punto debemos recordar a Ecequiela Cardona "Sequielita" y María Cabrera, quienes lideraron los retornos de San José del Peñón y El Salado, respectivamente, siendo asesinada la última, en 2002, un año después de haber retornado a El Salado. Sin embargo, por lo general, los estudios de movilidad no prestan atención al papel cardinal de las mujeres en el retorno, y mucho menos a sus prácticas cotidianas en pro de reproducir la vida en territorios que antes fueron de muerte. Y cuando lo hacen, reproducen una perspectiva de producción de conocimiento problemática, con abundantes críticas desde el feminismo latinoamericano, descolonial y poscolonial, como es la de "género" (Gregorio, 2012), pues dicha perspectiva suele partir 
de una "bio-lógica" para dar cuenta de las realidades de las personas, lo que invisibiliza las relaciones de poder que no solo "inventan" a las mujeres - la división cultural de los cuerpos- (Oy'wùmí, 2017), sino también aquellas que participan del ejercicio de investigar $y$, de esta manera, terminan consolidando la hegemonía patriarcal y colonial del conocimiento, al desplazar las voces de las mujeres en pro de una "corrección" política, y debilitando o banalizando su acción política (Ahmed, 2004; Enloe, 1991; Mohanty, 1984).

\section{Recoger mis pasos}

Ahí ella, frente a su casa, recostada en una pared de adobe que se niega a caer. Mira de frente ese horizonte verde de Mampujan, ${ }^{5}$ tan lleno de calor y polvo. Su casa - aquella por la que migra a Venezuela para trabajar y poder regresar a su pueblo con algo de dinero-, edificada no hace tanto tiempo, parece tan vieja como los sueños de progreso que hicieron posible su construcción. La maleza la ha "enmontado" sin piedad. Ahora es imposible imaginar que esa casa en ruinas albergó el primer aparato refrigerador del pueblo. Es una postal de fantasmas y no lo es. El 10 de marzo de 2000 un grupo de paramilitares del Bloque Héroes de Los Montes de María arriba al pueblo y amenaza con matar a la gente, lo cual obliga a que se desplacen 245 familias, alrededor de 1400 personas, quienes deben abandonarlo todo.

Con un plazo de 24 horas dado por los paramilitares, ella abandona su casa, su refrigerador, sus animales, sus cultivos, la "vida bonita", y emprende la huida con su familia: tía Rocina únicamente puede llevar el bastón que le permite caminar, y a tía Guada toca transportarla en hamaca, porque sus piernas no responden. La población desplazada llega hasta María La Baja con la expectativa de regresar a su Mampuján en breve. No sucede así, se ven confinados en albergues improvisados por poco más de tres años, y luego en un lote regalado por un cura donde van construyendo casas de zinc y madera. $\mathrm{Al}$ afrontar todos los problemas que supone este tipo de existencia - hacinamiento, enfermedad, aumento de la violencia- y la poca respuesta estatal en términos de proveer los servicios básicos, ella decide retornar, a sabiendas de que ese pueblo que recuerda de forma risueña, cantando cumbias, mamando "gallo", donde se siembra aguacate, yuca, ñame, se trabaja en el monte y se tienen puercos y gallinas (González, 2015), ya no existe.

Ella no es una figura singular, sino colectiva, al representar a tantas mujeres que, valientes, deciden retornar a los territorios de los cuales fueron expulsadas violentamente, afrontando todo lo que ello implica, en especial, la incertidumbre, la baja autoestima colectiva y el cansancio que semejante situación produce. Ella es un enunciado sin romanticismo, pues es claro que no todas las mujeres deciden retornar y que los principales motivos para el retorno, en el caso de las mujeres (Garzón, 2019), se relacionan con hallarse en estado de mayor vulnerabilidad social y económica en los lugares a donde se han desplazado, lo cual configura el retorno como una apuesta hecha desde la subalternidad. En efecto, tanto los procesos migratorios como los de retorno están, parafraseando a María José Magliano (2015), cruzados por múltiples ejes de desigualdad que inciden directamente en la vida cotidiana de las personas, determinan el acceso a derechos y oportunidades y construyen lugares de privilegio y de exclusión. Aquí es importante tener en cuenta que la población de Los Montes de María es, primordialmente, una población racializada, para cuyos habitantes no es nuevo el despojo de sus territorios, pero tampoco la respuesta a estos mecanismos de control y exterminio en la que las mujeres han protagonizado las luchas. Luchas dadas, en el caso del retorno que interesa en estas páginas, desde coordenadas diferentes a la gestión de recursos y la inserción al mundo del trabajo; es decir, no centradas en el ámbito "productivo", sino en el "reproductivo".

Entonces, iretornar? Sí. ¿Cómo? No hay respuestas certeras, pero sí una convicción: nos debemos fortalecer como mujeres y como comunidad desde prácticas "femeninas" - y feministas por su connotación política- que históricamente han urdido el tejido social y que, a veces, pasan desapercibidas como, por ejemplo, tejer, celebrar o cocinar. En efecto, como lo muestra Maroussia Hajdukowski-Ahmed (2008), en contextos extremos son las mujeres quienes suelen liderar procesos de resiliencia, en los que se conjugan agencias individuales y 
agencias históricas relacionadas con el mantenimiento de tradiciones, formas de espiritualidad, sentimientos y afectos, identidades culturales, resignificadas por las exigencias de un nuevo contexto. Por ejemplo, las mujeres en El Salado que deciden reactivar las fiestas patronales poco tiempo después del regreso, y lo hacen en la cancha donde ocurrió la masacre previa al desplazamiento forzado, o las mujeres de San José del Peñón que insisten en mantener la tradición de cocinar dulces para la semana santa estando o no en el exilio. Ello, sin embargo, no implica necesariamente un cambio radical en el orden social patriarcal (Gregorio, 2012), más bien una paradoja en su interior: el trabajo reproductivo de las mujeres erosiona ese orden y desmitifica la imagen de las mujeres como víctimas pasivas de los conflictos armados, sin olvidar que muchas de esas agencias, de esas "autonomías relativas" (Baylina y Salamaña, 2006), son habilitadas por ese mismo orden en el cual los trabajos del cuidado son asignados a las mujeres (Meertens,1994).

En el año 2005 - 14 de julio-, el bloque paramilitar Héroes de Los Montes de María de las Autodefensas Unidas de Colombia (AUC) se desmoviliza, lo que produce una disminución de la violencia en la zona; sin embargo, aún no existen condiciones del todo favorables para el retorno, en particular aquellas que tienen que ver con el mundo subjetivo, el miedo, el trauma, la elaboración del duelo. Por esa misma época, a la zona llega la misionera menonita Teresa Geiser, quien tiene experiencia con la superación del trauma, e invita a las mujeres a tejer con la finalidad de plasmar sus recuerdos en tela y, asimismo, sus visiones de futuro:

Las primeras puntadas fueron de dolor. Cada vez que entraba la aguja para unir las telas, algo se desgarraba en su corazón y el llanto salía sin parar. Entonces estas mujeres soltaban la aguja y se secaban las lágrimas para seguir llorando. La colcha de retazos apenas tenía forma: unas montañas de fondo, unos caminos, algunos árboles y el arroyo; ahora tenían que dibujar las personas. Cada figura representaba a un vecino, amigo o familiar. Por eso dolía tanto, porque lo que estaban plasmando en la tela era su propia historia.
Entonces después de secarse las lágrimas una y otra vez, de tomar aire y elevar una oración, volvían a tomar la aguja para ponerle ropa a cada figura humana. "El hermano Luis tenía un pantalón así", decía la una; "la ‘seño' Guadalupe tenía su pelito blanco muy blanco”, contestaba otra al extremo opuesto del tejido. Cada mujer aportaba un recuerdo, una idea, un pedazo de tela. Así construyeron su primer tapiz. Desplazamiento, se llamó. Así, sin eufemismos ni adornos (Castrillón, 2015:párr.1).

El tejido las une, les permite hablar entre ellas en un contexto de confianza, con el objetivo de poner en palabras lo que significa el desplazamiento forzado y sus avatares, también su lugar en él, es decir, les permite la construcción de una conciencia política: "en esta comunidad machista, la mujer era ama de casa y había pocas líderes. Nos dimos cuenta de que las heridas habían sanado mal, hicimos una catarsis", recuerda Juana Alicia Ruiz (citada en Castrillón, 2015:párr.7). Entonces, un grupo de quince tejedoras pasan de ser aprendices de una técnica de tejido nueva para ellas - tela sobre tela o quitling-, a ser agentes de procesos de organización, sanación, resiliencia y memoria histórica a través de los cuales no solo recrean imágenes de la violencia perpetrada en su comunidad, también aquellas de largo plazo que deja la colonialidad (Shepard, 2019). De esta manera, "los tejidos se volvieron en el catalizador de las mujeres para liberar el llanto. Al principio dolía recordar y sus tejidos fueron tristes y crudos. Luego, cuando los recuerdos dejaron de doler, los tejidos empezaron a llenarse de sueños y de imágenes del viejo y del nuevo Mampuján" (González, 2015:párr. 31).

En efecto, la práctica de tejer no solo tiene que ver con la sobrevivencia diaria en términos de, por ejemplo, proveer vestido. También es una práctica política en términos de agencia: construir un yo crítico de su entorno, dar nuevos significados - resignificar- al mundo del trabajo reproductivo, crear lazos comunitarios, dar testimonio de la vida de las mujeres, hacer memoria, apostar por las culturas vivas indígenas, afro y campesinas y, tal vez, lo más importante: construir redes de enseñanza-aprendizaje entre más mujeres en 
pro de sensibilizarlas sobre sus realidades a través del acto creador. Tejer, en este caso, es hacer un activismo textil feminista (Sánchez, Pérez y Chocontá, 2019). Al darse cuenta del efecto sanador del tejido y sus implicaciones políticas en el sentido de construir liderazgos de mujeres en la comunidad desplazada, este grupo de mujeres decide que deben compartir la experiencia con otras mujeres, para brindar a través de ella una formación política y de sanación:

Y esa resistencia se basa en reconocerse con las otras como iguales, en la solidaridad, el apoyo mutuo y la organización. Las formas de afrontamiento suponen también maneras de poner en cuestión sus roles establecidos socialmente. Tomar protagonismo público y organizarse como mujeres; reivindicar su papel en la defensa de la vida y los cambios en las relaciones de subordinación que la cultura patriarcal ha mantenido. La denuncia y la reivindicación de sus derechos suponen no sólo el aprendizaje de las leyes y sus derechos, sino sobre todo el ejercicio de la persistencia y una reconceptualización de sí mismas como sujetas de derechos y no como objeto de ayuda o de consuelo (Ruta Pacífica de las Mujeres, 2013:20).

En consecuencia, ella y las mujeres tejedoras de Mampuján retornan a sus territorios no para afincarse aún de nuevo en ellos, e inician la "ruta por la vida", una iniciativa que las lleva a recorrer los mismos lugares que recorren los paramilitares, pero esta vez con el fin de sembrar esperanza y vida; en otras palabras, resistir al conflicto, alcanzar sus derechos y promover relaciones desde otros paradigmas, incluido el perdón. Ciertamente:

Además de construir la memoria, estas mujeres se convirtieron en motor de un proceso de reconciliación, en el que participaron también los hombres, y que es inédito en el país: la comunidad de Mampuján perdonó a sus victimarios, líderes del Bloque Héroes de los Montes de María, entre ellos, Juancho Dique y Diego Vecino. El hecho culminante se vivió en las audiencias del incidente de reparación que se cumplió entre el 26 de abril y el 10 de mayo de 2010 (Castrillón, 2015:párr. 15).

Nace, en consecuencia, el grupo de tejedoras de Mampuján: "Mujeres tejedoras de sueños y sabores de paz". ${ }^{6}$ Una experiencia organizativa fundamental en Los Montes de María, la cual ha perdurado en el tiempo, con sus idas y venidas, obstáculos y retos, alianzas y autonomías, realizando una labor esencial, tanto en el interior de la región, como en el país y a nivel internacional. Dos de sus telares - "Desplazamiento" y "Masacre"- hacen parte del Museo Nacional, en la sala de Nación y Memoria y, hoy, su hacer va más allá de los tejidos e incluye otras apuestas como la producción de alimentos orgánicos y la organización de cooperativas. Así las cosas:

La creación de los tejidos en grupo, las actividades colectivas entre cocinar, conversar y representar los hechos como ejercicio para construir un ambiente de recuperación emocional, han trascendido y alcanzado un nivel de concretización en el plano de la movilización, militancia y construcción de redes para el tratamiento jurídico de sus reivindicaciones, redes de solidaridad con otras mujeres a nivel nacional también víctimas del conflicto, redes de memoria y voz, redes de emprendimiento (Ruiz, 2019:71).

Ahí ella, frente a su casa en ruinas. Suele visitarla de vez en cuando. Sabe que ha transitado un camino doloroso que la lleva a recoger sus pasos por aquellos paisajes que una vez fueron su territorio y que tal vez, algún día, lo vuelvan a ser. Pero no por ahora, pues el retorno a Mampuján —el viejo - tal vez sea tan solo una añoranza. El tiempo ha pasado, la comunidad ha ido edificando de a pocos el nuevo Mampuján en ese terreno regalado tiempo atrás por un cura, y los más jóvenes no desean regresar, ahora tienen otra vida. Ella ha aprendido del daño, el perdón, la resistencia y la agencia con una aguja en la mano. Ahora ha decidido no tejer más sobre el dolor, sino sobre la "vida buena". ¿Quién lo iba a pensar? Aquella actividad que aprendió de su madre y de su abuela, y que pensó era parte de lo que 
tenía que hacer como mujer, le dio nuevas herramientas para construir su experiencia y existencia como mujer, como desplazada y como retornada, pues aunque no se ha establecido de nuevo en su casa, sí ha regresado a su territorio por medio del tejido, el anhelo y la esperanza, y lo seguirá haciendo, junto con muchas otras mujeres para quienes los cuerpos pueden estar divididos, pero no los corazones que saben que pertenecen a ese pueblo donde se respira campo. Y no importa el tiempo transcurrido ni si existen hoy en día suficientes condiciones para el retorno; ella, como Iluminada -otra tejedora de Mampuján—, como tantas otras, han decidido: "así vieja como estoy, que me lleven a mi rancho, me voy para allá así sea a morir. Y si me muero acá, que me entierren allá" (citada en González, 2015:párr. 53).

\section{Empezar de nuevo}

Ella tiene un machete en mano. No le asusta esa visión: aquel patio donde solía sembrar, tener los árboles de aguacate y criar sus gallinas y dos puercos se encuentra invadido por la maleza, al punto que es difícil ver algo más que eso, maleza. Es una imagen generalizada en San Juan Nepomuceno — departamento de Bolívar - después del fatídico 30 de agosto de 2002, cuando empieza la masacre que expulsa a su población. ${ }^{7}$ Muchos años han pasado y la justicia no llega, ni la reparación, ni los recursos económicos prometidos por el Estado, ni la redistribución de las tierras. Tampoco importa, nunca han contado con los hombres de corbata de la capital para existir, hacer comunidad y vivir sus vidas. Ella, como varias otras mujeres de Los Montes de María, ha tomado la decisión de regresar a casa y reconstruir su mundo: "y, en medio del llanto, y de no saber qué hacer, salimos a caminar para tomar aire y refrescar las ideas. Ahí nació el proyecto de retornar, eso es lo que tenemos que hacer" (Montaño, 2015:párr.1l). Entonces, se debe limpiar la maleza del patio, preparar la tierra para sembrar y cerciorarse de que no haya artefactos explosivos abandonados por ahí. Con esa firmeza que la impulsa a retornar, ella alza su machete y empieza a trabajar, con el sol en su cabeza, el olor a tierra en sus sentidos y la esperanza de volver a pertenecer a su corazón.
Los retornos que se han producido en la región de Los Montes de María han sido de distinta índole. Algunos, como en el caso de las tejedoras, se realizan a través de la imaginación y la memoria, la representación de lo que fue y será y los desplazamientos físicos hacia los lugares sin fines de quedarse. Otros apuestan por regresar y quedarse, los cuales, por el paisaje de ruinas que propone el retorno y las condiciones económicas, sociales, subjetivas y políticas en el que se realiza, no pueden ser significados de otra manera que un "empezar de nuevo". Estos últimos, en especial, tienen que afrontar diferentes retos y luchas: por el abandono no hay en donde cultivar, ni servicios básicos, ni carreteras que conecten a los pueblos con las ciudades en pro de la reactivación del comercio, mucho menos hay un centro médico o una escuela. Para colmo, se debe enfrentar a terratenientes que no contentos con poseer vastas extensiones de tierra, siguen acaparando, comprando a precios bajos o expropiando tierras. En este contexto muchas mujeres, apoyadas en experiencias organizativas como la de las tejedoras de Mampuján, activan una serie de recursos para reinventarse, resignificarse y reconstruirse a ellas mismas, sus existencias y sus comunidades, en medio de condiciones adversas que, no obstante, son consideradas menos agresivas que las que han sufrido en los lugares a donde se desplazaron:

Creo que retornamos fue en el 2002 y es que nosotras aquí en el campo estábamos acostumbrados a tantafruta y allá en Sincelejo [lugar a donde fueron desplazadas] nos provocaba un manguito y no lo podíamos comprar porque era muy caro. Entonces por todo eso nos vinimos para acá... a darle [trabajar] (Entrevista a mujer joven, 2008, en Hernández, 2010:166).

\section{Además:}

Yo decidí venirme para acá, porque en esos oficios que yo me la pasaba allá, me la pasaba era enferma y yendo pa'l médico y yo de dónde, entonces yo dije: así muera, me voy para allá. Las condiciones en las que yo estaba no eran para estar en Sincelejo. Yo estoy contenta y 
alegre y le pido a dios que me tenga así como me tiene, que me dé corazón y valor para está' aquí, yo me siento aquí más tranquila. Aunque no tengo nada. Aquí me la paso haciendo galleta', hago pa' vendé' para compra' mi libra de arroz" (Entrevista a adulta mayor, 2008, en Hernández, 2010:166).

Lo primero es limpiar la casa, adecuarla para poder vivir en ella: "mi casa la encontré toda curtida [sucia] y ponerme a tirar machete. A mí me tocó hacer todos los oficios" (Garzón, 2019), cuenta Sequielita, lideresa del retorno a San Juan Nepomuceno. En efecto, en el primer momento del retorno con fines de arraigarse son las mujeres quienes cortan la maleza que ha crecido en paredes y techos de las viviendas; barren esas casas en ruinas para despejar zonas donde ubicar cocina, baño, lugares para dormir y una mesa improvisada para comer; buscan artefactos explosivos olvidados en medio de las confrontaciones armadas; recolectan madera y prenden el fuego. Además, implementan diferentes estrategias para espantar mosquitos, serpientes y otros animales que a causa del abandono se toman las calles del poblado. Por último, bajo su responsabilidad está la consecución de agua, fruta y verdura crecidas de forma silvestre, velas para mantener iluminado el lugar y otros recursos que son necesarios para sobrevivir. A propósito, cuenta una mujer retornada de El Salado: "yo me quedé con Mariela aquí, íbamos a los pozos, recogíamos el agua, cocinábamos. [Y así] ya la gente comenzó a retornar [aunque] con miedo" (Garzón, 2014:5).

Ciertamente, el retorno se hace en condiciones materiales semejantes a las que se hizo el desplazamiento; es decir, con muy pocas pertenencias y animales, con un casi nulo apoyo estatal, pues aquí como allá la situación de pobreza no cambia con el tiempo y sigue imperando el miedo a otra masacre, a otro desplazamiento. Entonces, mientras se comienza a cultivar es preciso hallar alimento silvestre, cazar animales de monte y obtener aguas de ríos o riachuelos. En consecuencia, reconstruir la vida cotidiana, sus rutinas, espacios y prácticas, insisto, es el primer gran reto que asumen las mujeres retornadas en su regreso (Reyes, 2003). En este sentido, la reconstrucción de la vida colectiva, en un escenario familiar que resulta diferente, le asigna a las mujeres una serie de tareas que, desde la división sexual del trabajo por razones de género, les corresponde en apariencia (Garzón, 2019). Indudablemente, la división sexual del trabajo y la atribución de los trabajos del cuidado a las mujeres son una cuestión política, de relaciones de poder, y no un hecho natural, enmarcadas ambas en genealogías de explotación colonial y capitalista, pero también en genealogías de resistencias y reconfiguración del trabajo de reproducción de la vida; y más en la actualidad, cuando sabemos que es a través del trabajo doméstico, de cuidados, de reproducción de la vida, que las "mujeres sujetan más de la mitad del cielo" (Federici, 2013:117).

En tanto estas labores de reproducción de la vida, en este contexto, no se realizan de forma solitaria, empiezan a configurar un escenario político donde las retornadas discuten los sentidos de su hacer, pues, como se ha dicho, los liderazgos de las mujeres socavan el orden patriarcal —aunque muchas veces no logran derribarlo del todo- - y buena parte de los horizontes de futuro de las mujeres retornadas tienen que ver con condiciones de mayor bienestar para ellas como mujeres. Así, en medio de las actividades de desmonte, búsqueda de agua o preparación de alimentos, ellas debaten qué desean en ese lugar que están reconstruyendo y cómo quieren que sean sus vidas. Es importante decir aquí que muchas de las retornadas de Los Montes de María son mujeres víctimas de violencia doméstica y de violencia sexual ejercida por actores armados, lo que genera alianzas solidarias que implican transformaciones individuales y colectivas, cambios profundos en las maneras de pensar, de sentir y de relacionarse con las otras y de exigir justicia, como afirma una mujer desplazada del Carmen de Bolívar:

[...] pues no, en el inicio no lo veía así; yo pensaba que cada una tenía que vivir la vida y valerse como pudiera, pero al ver tantas cosas que le han pasado a uno, la obligan a tener ese respeto hacia las demás y valorarlas, y hacer también que se les respete y a luchar por aquellas personas que uno sabe que son capaces de salir adelante (Ruta Pacífica de las Mujeres, 2013:411). 
Emerge, en consecuencia, tanto una conciencia política a propósito de qué significa ser una mujer retornada, como el proyecto de organizarse en pro de la construcción de esa vida digna que les dota de agencia: "decidimos organizarnos por nuestro bienestar", comenta una mujer de San José del Peñón. Indudablemente:

[...] a pesar de haber sido despojadas de sus medios de vida o arrancadas de los lugares donde ellas desempeñaban un papel en el tejido social y comunitario, su capacidad de tejer relaciones les ayudó a rehacerse como mujeres, recomponiendo a su vez el entramado afectivo cercano y participando muchas veces en organizaciones y proyectos comunitarios (Ruta Pacífica de las Mujeres, 2013:75).

De ahí que la necesidad de compartir con otras mujeres, sumada a las experiencias adquiridas durante el exilio y la tradición organizativa de la región de Los Montes de María, genera un escenario que potencia la organización femenina en el retorno, en el que destacan organizaciones como: Mujeres Unidas de El Salado, ${ }^{8}$ Narrar para Vivir ${ }^{9}$ en San José del Peñón o las Mujeres Tejedoras de Mampuján, que cumplen un papel fundamental en reforzar la idea de comunidad, darle continuidad al proyecto colectivo y generar integración en torno a este (Garzón, 2019).

Paralelo al proceso anterior se da un segundo reto que se relaciona con la adecuación del paisaje y de la infraestructura de los poblados abandonados para hacerlos habitables de nuevo. Este convoca esfuerzos comunitarios para asumir tareas como las de seguridad, interlocución con el Estado y cohesión de la población en torno al proyecto de retorno, los que, a su vez, redundan en la construcción y fortalecimiento de lazos sociales que, rotos por el exilio y la desconfianza impuesta desde la lógica de la violencia, comienzan a tejerse de nuevo y son fundamentales, porque: "los espacios familiares y el sentido de vecindad se constituyeron en partes fundamentales del devenir de la misma comunidad" (Ospina, 2013:87). Aquí las mujeres también son líderes, pues, como bien lo dice la Ruta Pacífica de las Mujeres (2013), afrontar las violencias del conflicto armado y las violaciones sistemáticas de los derechos humanos transforma a las mujeres de manera íntima e, igualmente, en su forma de habitar el mundo ahora guiada por una conciencia política y un accionar en consecuencia, capaz de reaccionar frente a la injusticia de forma no sumisa. En este punto del camino, el cambio en la cultura es fundamental y se transforma en motivo de lucha, pues "empezar de nuevo" supone no hacerlo desde parámetros patriarcales que ubican a los hombres en el centro de la existencia, y más bien ubicar la vida - "la vida buena" - en ese lugar.

Así es como en el ámbito del trabajo mixto las mujeres se hacen partícipes de los acuerdos y los trabajos relacionados con el bienestar colectivo, desde nuevos lugares de negociación, ya no como "complementos de", sino como protagonistas que agencian de manera cardinal las estrategias para resolver la subsistencia, la protección, la comunicación, la participación de todas las personas en la comunidad. En este escenario, sus deseos, motivaciones, voces, destrezas y creatividades -muchas de ellas descubiertas en el proceso mismo del retorno - son puestas sobre la mesa a la hora de negociar una vida comunitaria en conjunción con lo que ello supone en el día a día, en un contexto de desprotección del Estado, escasos recursos y la necesidad imperante de proveer alimentos, seguridad, higiene y cuidado. El ejercicio organizativo ha permitido que las retornadas se reconozcan como hacedoras de sus vidas y de la vida comunitaria, y entender que aquellos mandatos que las someten a la subordinación pueden ser transformados y están siendo transformados: "bueno, ahora estamos contentos y felices con la comunidad porque ahora estamos los mismos, con los hijos, trabajando, no se ve nada malo... estamos viviendo juntos, estamos acá..." (Entrevista a mujer adulta, 2008, citada en Hernández, 2010:175).

Finalmente, se suma un tercer reto que se asocia con construir formas de resiliencia y de cuidados que implican seguridad y consuelo, la resignificación de una identidad colectiva, la construcción narrativa del retorno en pro de la edificación de memoria histórica y la constitución de una subjetividad -individual, colectiva - no desde la victimización, sino desde la 
agencia: "somos retornadas y eso es diferente", señala Maya de San José del Peñón con el tono fuerte de su voz. $\mathrm{Y}$, de nuevo, aquí son las mujeres quienes habilitan los procesos porque:

\begin{abstract}
A diferencia de otras formas de producción, la producción de seres humanos es irreductible —en la mayor parte de su extensión - a la mecanización, ya que requiere un alto grado de interacción humana y la satisfacción de necesidades complejas, en las que elementos físicos y afectivos están inextricablemente combinados. El hecho de que el trabajo reproductivo es un proceso de trabajo intensivo, es más evidente en el cuidado de las criaturas y de los ancianos, el cual abarca -incluso en sus parte más propiamente físicas - la provisión de una sensación de seguridad, consuelo y anticipación de posibles temores y deseos (Federici, 2013:66).
\end{abstract}

Con la persistencia que las caracteriza, muchas mujeres desplazadas insisten tercamente en que es posible proponer órdenes y prácticas diferentes a las legadas por una violencia histórica, por el patriarcado y la colonialidad, que las ha despojado de tierras, territorios y proyectos de vida, pero a la que responden mediante agencias y liderazgos, hasta el momento, desconocidos, tímidos o recurrentes. Entonces, mantener el ánimo, no desfallecer, no dejar que vecinos y vecinas declinen ante el temor, el esfuerzo y la precariedad, es otra de las tareas que asumen las mujeres. Y es una tarea esencial, un trabajo inmaterial central muchas veces poco valorado en tanto que es "invisible", aunque con efectos muy reales en la vida de las personas. En tal sentido, labores asociadas al cuidado, el apoyo y la supervivencia son argumentos para la organización femenina y su agencia: rehacer lazos desde la identificación como mujeres, mujeres retornadas, mujeres luchadoras, mujeres que añoran, como ellas mismas dicen: "Salir adelante". Cuidar, cuidarse y enseñar a cuidar en un contexto en el que cualquier tipo de liderazgo, organización colectiva o reclamo frente a los derechos de las comunidades significa poner en riesgo la vida.

\section{Regresar a casa}

Ensayar una mirada detallada a las prácticas desplegadas en el retorno por las mujeres, en este caso, a las formas y alcances de sus procesos organizativos, permite la elaboración de un horizonte interpretativo que, crítico frente a la mirada hegemónica del estudio de las movilidades forzadas, descentre su tendencia androcéntrica de leer a las mujeres como simples "seguidoras" de las decisiones masculinas, para ubicarlas en el lugar de agencia política que les corresponde. En Mampuján, por ejemplo, las mujeres organizadas alrededor del tejido, quienes retornan mediante la rememoración y el anhelo, ubican su proceso como un caso ejemplar de reconstrucción individual y colectivo en medio del conflicto armado, pero también movilizan agendas relacionadas con el reconocimiento de su identidad afrodescendiente y sus derechos históricos sobre el territorio. Por su parte, las mujeres que integran la organización Narrar para Vivir de San Juan Nepomuceno o las Mujeres Unidas de El Salado han encontrado en la organización una plataforma para la formación de conciencia política, de sí mismas, de buscar opciones económicas, culturales y personales para reconstruir sus vidas, las de sus familias y las de sus comunidades.

Mediante sus tejidos, postres, charlas, cantos y bailes, trabajos del cuidado y de la reproducción de la vida, las retornadas que sueñan con regresar a casa o las que ya lo han hecho narran historias que resignifican biografías y reconstruyen existencias -individuales, colectivas - fuertemente marcadas por la violencia del conflicto armado y el desplazamiento forzado, pero que se niegan a permanecer en la victimización y la inmovilidad reclamando agencias en la construcción de vidas propias, territorios propios. Su experiencia representa el valor político de los trabajos de reproducción de la vida en el marco del retorno que, sumados a la emergencia de una conciencia política, organización y liderazgos, hace posible la reconstrucción de la vida. En ese sentido, construir un acercamiento testimonial como los hilos que urden un tejido y, al mismo tiempo, caminos de retorno, es necesario ya que permite poner la experiencia y las voces de las mujeres retornadas en 
un primer lugar, dotándolas, como se dijo antes, de un valor político cardinal en aras de la reconstrucción de la vida. En efecto, las mujeres retornadas luchan por permanecer, pero no se conforman con eso, reclaman estabilidad, reconocimiento y, especialmente, dignidad, voz y memoria. Ellas, las retornadas, han regresado a casa - como regresa el viento-, por el camino viejo, recogiendo sus pasos para empezar de nuevo.

\section{Notas}

${ }^{1}$ Hace referencia a maletas, mochilas, bultos con elementos de la casa como ropa, ollas, etcétera.

2 Son del cancionero popular colombiano: "La muerte me vino a buscar", del compositor Nando Coba, sin fecha de publicación.

${ }^{3}$ La región está conformada, en el departamento de Bolívar, por los municipios de María La Baja, San Juan Nepomuceno, El Guamo, San Jacinto, El Carmen de Bolívar, Zambrano, Córdoba y, en el departamento de Sucre, por San Onofre, Los Palmitos, Morroa, Chalán, Colosó, Ovejas, San Antonio de Palmito y Toluviejo.

${ }^{4}$ A propósito, revisar: Garzón (2014).

${ }^{5}$ Corregimiento del municipio de María La Baja, en Los Montes de María, departamento de Bolívar, Colombia.

${ }^{6}$ Es importante destacar otras formas de organización de mujeres en la región que han sido protagonistas de las luchas en contra del conflicto armado y su violencia en Colombia: Red de Solidaridad: Mujeres por Colombia, Corporación de Mujeres Orocoma, Cooperativa Agropecuaria de Mujeres del Valle Encantado, Red de Mujeres del Caribe y Colectivo de Comunicaciones Montes de Marida Línea 21.

${ }^{7}$ Hace referencia a la masacre conocida como Los Guáimaros y El Tapón, por las fincas donde ocurrieron los hechos perpetrados entre el 30 y el 31 de agosto de 2002, con un saldo de quince víctimas y el posterior desplazamiento de las personas sobrevivientes a municipios cercanos. Esta masacre es la tercera más numerosa en Los Montes de María. Hasta el día de hoy no se conoce a los autores intelectuales y materiales del hecho, por lo que tampoco existe un proceso de justicia y reparación.
${ }^{8}$ La organización busca el desarrollo productivo del corregimiento y la incidencia en las políticas públicas que se implementan en la región.

${ }^{9}$ Realiza labores de apoyo psicosocial, económico, productivo y jurídico a mujeres que han sufrido diversas victimizaciones a causa del conflicto armado.

\section{Referencias}

Ahmed, Sara (2004). "Affective economies". En Social Text, 22(2), 117-139.

Bach, Ana María (2010). Las voces de la experiencia: el viraje de la filosofía feminista. Buenos Aires. Biblos.

Baylina, Mireia e Isabel Salamaña (2006). "El lugar del género en la geografía rural”. En Boletín de la AGE, 41, 99-112.

Blitz, Brad (1999). "Balkan Returns: An Overview of Refugee Returns and Minority Repatriation". United States Institute of Peace, Special Report, 57. Disponible en http://www.usip.org/publications/balkan-returnsoverview-refugee-returns-and-minority-repatriation (consultado el 25 de marzo de 2010).

Caicedo, Luz Piedad, Daniel Manrique, Delma Millán y Belky Pulido (2006). Desplazamiento y retorno. Balance de una política. Retornos sin principios, desplazamientos sin final. Evaluación de la política de retorno del gobierno Álvaro Uribe. Bogotá: Publicaciones ILSA.

Castrillón, Gloria (2015). "Las tejedoras de Mampuján. La fuerza femenina del perdón”. En El Espectador, 19 de noviembre. Disponible en https://www.elespectador. $\mathrm{com} /$ cromos/hoy-historias-cronicas/las-tejedoras-demampujan-la-fuerza-femenina-del-perdon-16675

Centro de Memoria Histórica (s/f). "Recorridos por los paisajes de la violencia en Colombia: Montes de María". Disponible en http://www.centrodememoriahistorica. gov.co/micrositios/recorridos-por-paisajes-de-la-violencia/montes-maria.html

Coutin, Susan (2016). Exiled Home. Salvadoran trasnational youth in the aftermath of violence. Durham: Duke University Press.

Enloe, Cynthia (1991). “Women and Children': Propaganda Tools of Patriarchy" En G. Bates (ed.), Mobilising Democracy: Changing the US Role in the Middle East. Monroe: Common Courage Press. 
Federici, Silvia (2010). Calibán y la bruja. Mujeres, cuerpo y acumulación originaria, Madrid, Puebla y Oaxaca: Traficantes de sueños, Tinta Limón, Pez en el árbol, Labrando en Común.

Federici, Silvia (2013). La revolución feminista inacabada. Mujeres, reproducción social y lucha por lo común. México: Escuela Calpulli.

Garzón Martínez, María Angélica (2014). "Las narrativas del retorno”. En Revista Encuentros, 12 (2), pp. 67 77. Colombia: Universidad Autónoma del Caribe.

Garzón Martínez, María Angélica (2019). Tácticas del habitar. Prácticas de recuerdos y (re)significación de lugares en contextos de retorno de población. Bogotá: Centro de Estudios Sociales-Universidad Nacional de Colombia.

Gregorio Gil, Carmen (2012). “Tensiones conceptuales en la relación entre género y migraciones. Reflexiones desde la etnografía y la crítica feminista”. En Papers, 97(3), 569-590.

González, David (2015). "Historia de un éxodo: Mampuján”. En Vice, 21 de enero. Disponible en https:// www.vice.com/es_co/article/3b9wzn/bitacora-deun-exodo-llamado-mampujan

Hajdukowski-Ahmed, Maroussia (2008). "A Dialogical Approach to Identity: Implications for Refugee Women". En M. Hajdukowski-Ahmed, N. Kanlou y H. Moussa (eds.), Not Born A Refugee Woman. Contesting Identities, Rethinking Spaces. Oxford: Berghahn Books.

Hernández Mercado, Luisa Fernanda (2010). "Procesos de retorno y reubicación de dos comunidades victimizadas por el desplazamiento forzado en Los Montes de María". Trabajo de grado para optar al título de Magíster en Estudios Políticos, Universidad Nacional de Colombia. Disponible en http://www. bdigital.unal.edu.co/2719/1/697011.2010.pdf

Magliano, María José (2015). "Interseccionalidad y migraciones: potencialidades y desafíos". En Estudios Feministas, 23(3), septiembre-diciembre, 691-712.

Meertens, Donny (1994). Mujer y violencia en los conflictos rurales. Bogotá: Programa por la Paz.

Mohanty, Chandra Talpade (1984). "Under Western Eyes: Feminist Scholarship and Colonial Discourses". En Boundary, 2(12/13), 333-358.
Montaño, John (2015). "Mujeres sobrevivientes de El Salado hicieron primer retorno simbólico". En El Tiempo, 23 de agosto. Disponible en https://www.eltiempo.com/ archivo/documento/CMS-16276980

Ospina, Bryan (2013). Entre el irse y el volver: reconfiguración en las prácticas espaciales de campesinos retornados en los Montes de María. La Plata: Universidad de la Plata.

Oy’wùmí, Oyèrónk' (2017). La invención de las mujeres. Una perspectiva africana sobre los discursos occidentales del género. Bogotá: en la frontera.

Pécaut, Daniel (2002). "Hacia la desterritorialización de la guerra y de la resistencia civil". Ponencia presentada en el Seminario Internacional Dimensiones Territoriales de la Guerra y la Paz. Universidad Nacional de Colombia, Red de Estudios de Espacio y Territorio (RET), Bogotá.

Pettersson, Bjorn (2000). "Tierra cultivable y desplazamiento interno en Colombia". Migraciones forzadas, 7. Refugee Studie Centre, Consejo Noruego para los refugiados, Global IDP Survey. Disponible en http:// www.migracionesforzadas.org/pdf/RMF7/RMF7.pdf (consultado el 11 de junio de 2011).

PNUD Colombia (2010). Los Montes de María: análisis de la conflictividad. Bogotá: Asdi.

Reyes Zúñiga, Luisa Emilia (2003). "Narrando el retorno. Textos de mujeres retornadas guatemaltecas". En Diálogos Latinoamericanos, 8, 79-95.

Ruta Pacífica de las Mujeres (2013). La verdad de las mujeres. Víctimas del conflicto armado de Colombia, vol. 1, Bogotá: G2 Editores.

Ruiz, Yuli (2019). “Tejedoras de Mampuján: Violencia y Conflicto Armado en Colombia, experiencias estéticas para una política emancipadora”. Trabajo de Conclusión de Curso: Especialización en Derechos Humanos en América Latina, Universidad Federal de Integración Latinoamericana, Foz de Iguazú, Brasil.

Sánchez Aldana, Eliana, Tania Pérez Bustos y Alexandra Chocontá Piraquive (2019). “¿Qué son los activismos textiles?: una mirada desde los estudios feministas a catorce casos bogotanos". En Athenea Digital, 19(3), e2407, 1-24.

Shepard, Mathilda Eliza (2019). "Desplazamientos entretejidos: imaginarios transicionales y la diasporización de la memoria en los Tejidos de Mampuján". En Revista de Estudios Colombianos, 53, enero-junio, 74-87. 